\title{
The effect of training image and secondary data integration with multiple-point geostatistics in groundwater modelling
}

\author{
X. L. He ${ }^{1}$, T. O. Sonnenborg ${ }^{2}$, F. Jørgensen ${ }^{2}$, and K. H. Jensen ${ }^{1}$ \\ ${ }^{1}$ Department of Geosciences and Natural Resource Management, Copenhagen University, Copenhagen, Denmark \\ ${ }^{2}$ Geological Survey of Denmark and Greenland (GEUS), Copenhagen, Denmark \\ Correspondence to: X. L. He (xih@geo.ku.dk)
}

Received: 29 August 2013 - Published in Hydrol. Earth Syst. Sci. Discuss.: 26 September 2013

Revised: 16 June 2014 - Accepted: 23 June 2014 - Published: 7 August 2014

\begin{abstract}
Multiple-point geostatistical simulation (MPS) has recently become popular in stochastic hydrogeology, primarily because of its capability to derive multivariate distributions from a training image (TI). However, its application in three-dimensional (3-D) simulations has been constrained by the difficulty of constructing a 3-D TI. The object-based unconditional simulation program TiGenerator may be a useful tool in this regard; yet the applicability of such parametric training images has not been documented in detail. Another issue in MPS is the integration of multiple geophysical data. The proper way to retrieve and incorporate information from high-resolution geophysical data is still under discussion. In this study, MPS simulation was applied to different scenarios regarding the TI and soft conditioning. By comparing their output from simulations of groundwater flow and probabilistic capture zone, TI from both sources (directly converted from high-resolution geophysical data and generated by TiGenerator) yields comparable results, even for the probabilistic capture zones, which are highly sensitive to the geological architecture. This study also suggests that soft conditioning in MPS is a convenient and efficient way of integrating secondary data such as 3-D airborne electromagnetic data (SkyTEM), but over-conditioning has to be avoided.
\end{abstract}

\section{Introduction}

Aquifer heterogeneity is one of the severe challenges in groundwater flow simulation and with limited number of observations it is always difficult to depict the complete subsurface geology. Hence, statistical methods are often used to estimate geological heterogeneity. Various geosta- tistical methods have been developed, including variogrambased techniques (Delhomme, 1979; Deutsch and Journel, 1992; Wingle and Poeter, 1993; Johnson, 1995; Klise et al., 2009), the transition probability-based method (Carle and Fogg, 1996), object-based modelling (Deutsch and Wang, 1996) and the multiple-point geostatistical approach (MPS) (Journel, 1993; Guardiano and Srivastava, 1993; Strebelle, 2002). Most of these methods require observations to draw correlation, and some even have the ability to integrate multiple sources of observations. With the development in geophysical technology, high-resolution geophysical mapping techniques are now available, such as magnetic resonance sounding (MRS) (Lubczynski and Roy, 2003), airborne electromagnetic system SkyTEM (Sørensen and Auken, 2004), satellite remote sensing (Hoffmann, 2005), and ground penetrating radar (GPR) (Clement and Ward, 2008). Bourges et al. (2012) illustrated different ways of applying gravity data, refraction seismic data and borehole data with geostatistical methods. However, the proper method to incorporate these data into a geostatistical simulation is still a subject of active research.

The theory of multiple-point geostatistics has been developed over the last two decades. An important development was the pixel-based single normal equation simulation algorithm (SNESIM) proposed by Strebelle (2002), which allowed for simulations with reasonable computational power. The primary advantage of MPS is its capability to capture multiple-point-based structure information instead of using two-point-based statistics (variogram) (Journel, 2005). The database from which the structural information is retrieved is referred to as a training image (TI). Comunian et al. (2011) pointed out that a 3-D (three-dimensional) TI is 
necessary for 3-D MPS simulation, but it is not trivial to generate a 3-D TI since geological observations generally only provide 2-D information. Hence, 3-D applications are one of the most important challenges for MPS (Huysmans and Dassargures, 2009). Okabe and Blunt (2005) as well as Okabe and Blunt (2007) generated 3-D TI realizations by applying information from lateral 2-D images on orthogonal directions. Coz et al. (2011) built a 3-D TI by successively replicating a single 2-D TI. These "copy and paste" methods are simple but certain assumptions need to be invoked. Other methods include complicated statistical simulations such as Comunian et al. (2011) and Comunian et al. (2012). They used probability aggregation approaches to retrieve statistical information from 2-D TIs which subsequently were applied to simulate a 3-D TI. Maharaja (2008) proposed a simple object-based algorithm, TiGenerator, to generate parametric images. However, an image purely generated by stochastic methods lacks evidence from geological observations, and its application in MPS can be questioned. Huysmans and Dassargures (2009) concluded that the sensitivity of the model predictions to the training image is an interesting topic for further research.

Another advantage of MPS is the ability to incorporate multiple sources of data (Liu et al., 2005; Strebelle, 2006; Hu and Chugunova, 2008). With the flourishing of new measurement techniques, geological observations with relatively high resolution and accuracy are available, and integrating them into stochastic simulations is appealing. Liu et al. (2004) demonstrated how the integration of seismic data reduces the uncertainty in geofacies simulation. Other studies (Strebelle et al., 2002; Huysmans and Dassargues, 2012) also applied soft data conditioning in MPS, but the specific effect of soft data conditioning on the groundwater flow regime has rarely been studied.

The objective of this study is to evaluate the sensitivity of different training images and soft data in MPS and to explore the extent to which this sensitivity propagates in groundwater flow simulations. Four scenarios of MPS simulations are designed with different combination of TI and soft data to provide suggestions regarding the applicability of MPS. The simulated geological models are incorporated into a steady state groundwater model and each model is calibrated against field observations. The results are analysed based on estimated hydraulic conductivity, simulated hydraulic head and stochastic capture zone.

\section{Study area and data}

The study area covers a $14.5 \mathrm{~km}$ by $13.9 \mathrm{~km}$ region located near the town of Ølgod in western Denmark (Fig. 1). This region is dominated by arable land with inland marsh around seven streams. The land surface elevation in this area reaches to about $64 \mathrm{~m}$ above mean sea level (a.s.l.) in the northwestern part, and decreases to around $17 \mathrm{~m}$ a.s.l. in the southeast-

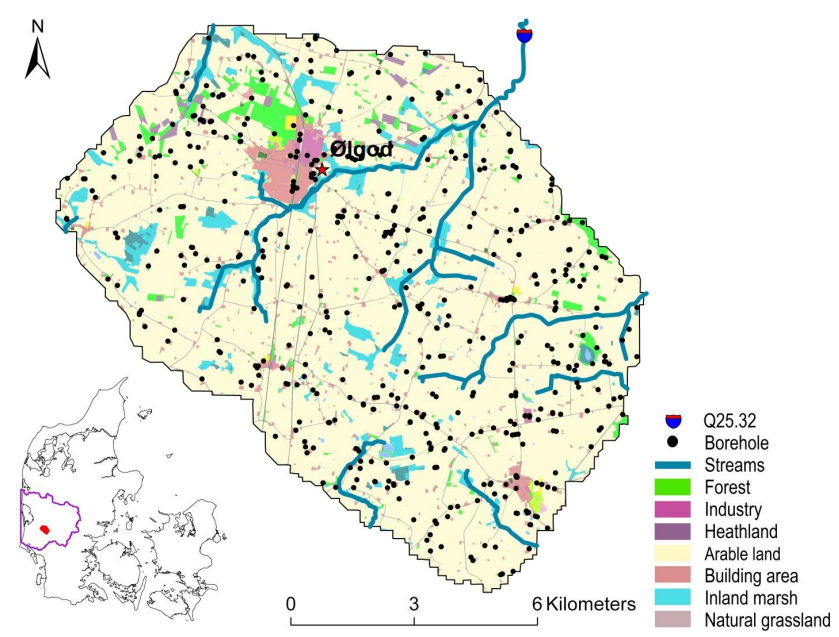

Figure 1. Location and land use of the study area. Black points denote the 525 boreholes whose logs were used as hard data in the geostatistical simulations.

ern part. The climate is characterized by mean temperatures ranging from $1.4{ }^{\circ} \mathrm{C}$ in January to $16.5^{\circ} \mathrm{C}$ in August with an annual average around $8.2^{\circ} \mathrm{C}$. Precipitation is highest in autumn and winter while spring is relatively dry, the average annual precipitation is approximately $1050 \mathrm{~mm} \mathrm{year}^{-1}$ (Stisen et al., 2011). According to the National Water Resources Model (DK-model; Henriksen et al., 2003), the annual average groundwater recharge is $611 \mathrm{~mm} \mathrm{year}^{-1}$. Water consumption primarily relies on groundwater abstraction. In the Danish national geological JUPITER database (http: //www.geus.dk/jupiter/index-dk.htm), there are 165 pumping wells in this area with a total mean abstraction of $3.2 \times 10^{6} \mathrm{~m}^{3}$ year $^{-1}$ in the period from 2000 to 2010 .

Figure 2 shows the regional geology of the study area as described by Scharling et al. (2009) based on hydrostratigraphic modelling. This regional-scale model was primarily intended to establish the Miocene successions in western Denmark, while less effort was devoted to the modelling of the Quaternary sediments. This model indicates that below elevations of $-70 \mathrm{~m}$ a.s.l., the geology in the study area is dominated by Miocene sediments. Intensive geological mapping in the study area including borehole logs, seismic surveys and airborne transient electromagnetic (SkyTEM) investigations show that the geology at elevations above $-70 \mathrm{~m}$ a.s.l. is dominated by highly heterogeneous Quaternary sediments with variable thickness (Høyer et al., 2011). Below, Miocene deposits are located with a thickness of up to about $150 \mathrm{~m}$ followed by a Palaeogene clay at the bottom (Rasmussen et al., 2010). Accordingly, the geological settings have been conceptualized into five units: Quaternary sand, Quaternary clay, Miocene sand, Miocene clay and Palaeogene clay.

The JUPITER database holds lithology logs of 525 boreholes in the study area (Fig. 1), but most of the boreholes are 

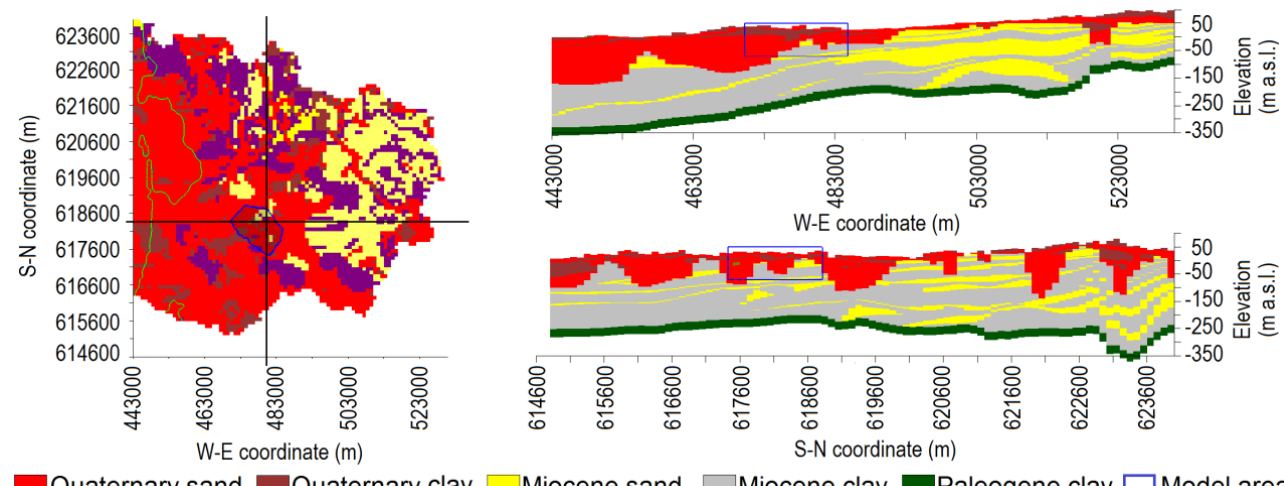

Quaternary sand Quaternary clay

Miocene sand

Miocene clay $\square$ Paleogene clay $\square$ Model area

Figure 2. Regional geological structure, model area in this study is marked with a blue frame. The location is marked by the purple polygon in Fig. 1, and the horizontal plane is taken at $10 \mathrm{~m}$ a.s.l. (modified after Scharling et al., 2009).

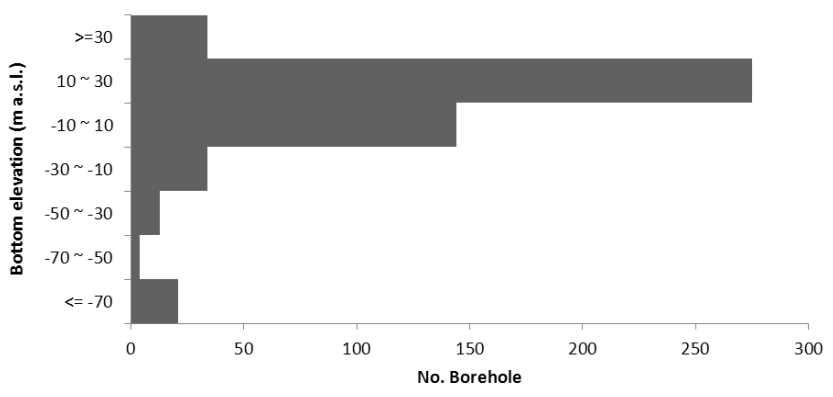

Figure 3. Bottom elevation of boreholes in the model area. In total there are 525 boreholes, but only 22 boreholes are deeper than $-70 \mathrm{~m}$ a.s.l.

relatively shallow and only 22 boreholes reach deeper than $-70 \mathrm{~m}$ a.s.l. (Fig. 3). Therefore, the geological analysis and modelling were performed on Quaternary sediments from the surface down to $-70 \mathrm{~m}$ a.s.l.

Another important source of information is SkyTEM data (Høyer et al., 2011). The subsurface electrical resistivity data were collected with line spacing from 125 to $270 \mathrm{~m}$, and the soundings penetrated more than $200 \mathrm{~m}$ down. The resistivity data have been filtered and inverted using a 19-layer "smooth model", resulting in a 3-D resistivity data set with cell size of $100 \mathrm{~m} \times 100 \mathrm{~m} \times 5 \mathrm{~m}$ (Høyer et al., 2011). With its high resolution, SkyTEM data are ideal as soft probability data or training image for MPS simulation.

\section{Methodology}

\subsection{Multiple-point geostatistics}

MPS was first presented as a direct algorithm in stochastic simulation by Guardiano and Srivastava (1993). Later, Strebelle (2002) introduced the SNESIM algorithm which combines the flexibility of the pixel-based algorithm and the ability to reproduce crisp shapes of the object-based algorithm.
The critical information of sequential simulation is the conditional probability distribution function (cpdf), and in the SNESIM algorithm the cpdf of a random variable $\boldsymbol{S}(\boldsymbol{U})$ is solved by the following equation:

$P\left(\boldsymbol{S}(\boldsymbol{U})=S_{k} \mid d_{n}\right) \cong \frac{c_{k}\left(d_{n}\right)}{c\left(d_{n}\right)} k=1, \ldots, K$

where $\boldsymbol{U}$ denotes an arbitrary location, and $k$ denotes a certain class of lithology, which can have $K$ categories in total. $d_{n}$ denotes the data event with $n$ data points included and is obtained by scanning the TI with a search template consisting of $n+1$ nodes centred at location $\boldsymbol{U} . c\left(d_{n}\right)$ denotes the number of replicates of a certain conditioning data event $d_{n}$, and $c_{k}\left(d_{n}\right)$ denotes the number of replicates in $c\left(d_{n}\right)$ where the central node $\boldsymbol{U}$ has the random variable $\boldsymbol{S}(\boldsymbol{U})=S_{k}$. Therefore, Eq. (1) implies that the probability of state $S_{k}$ to occur at location $\boldsymbol{U}$ with conditioning data event $d_{n}$ equals to the proportion $c_{k}\left(d_{n}\right) / c\left(d_{n}\right)$ from a training image. The solution is achieved by scanning a training image. A training image is a conceptual 2-D or 3-D map which depicts the expected structure and pattern of facies (Strebelle, 2002).

In the practice of stochastic simulation, the cpdf is integrated with the sequential simulation paradigm (Goovaerts, 1997, p. 376). The hard data is first assigned to the closest grid nodes, and all the unsampled nodes are visited once and only once in a random path. At each unsampled node $\boldsymbol{U}$, the recorded cpdf corresponding to an actually present hard conditioning data event is retrieved and used to draw the simulated value $\boldsymbol{S}(\boldsymbol{U})$.

The software package SGeMS (Stanford Geostatistical Modelling Software) (Remy et al., 2009) was applied in this study. The MPS simulation was carried out using the simulation package snesim_std provided by SGeMS. The simulation included two categories, Quaternary sand and Quaternary clay, with target proportions set to 0.67 and 0.33 , respectively, as indicated by borehole data. As suggested by Liu (2006), the dimension parameter of the search template was based on the primary understanding of the geological 
structure, which can be indicated by TI1 (Table 1). The ellipsoid search template has 240 nodes, and the geometry was set to 2000, 2000 and $60 \mathrm{~m}$ for maximum, mean and minimum separately, without any rotation or affinity.

\subsection{Soft data conditioning}

Soft data or secondary data provide indirect information on the distribution of geological facies. Typical soft data include geophysical data such as seismic data, spaceborne geodetic observations, and airborne electromagnetic data. To be integrated in SNESIM, soft data first have to be converted into facies probability data (Strebelle, 2006). The cpdf based on both hard and soft data, $P(\mathrm{~A} \mid \mathrm{B}, \mathrm{C})$, where " $\mathrm{B}$ " indicates the hard data set and " $C$ " indicates the soft data set, is solved by deriving a Bayesian-based model of integrating $P(\mathrm{~A} \mid \mathrm{B})$ and $P(\mathrm{~A} \mid \mathrm{C})$ (Journel, 2002). In Bayesian statistical terms, $P(\mathrm{~A})$ is the facies global proportion or prior probability. And in this case, the notation $P\left(\boldsymbol{S}(\boldsymbol{U})=S_{k} \mid d_{n}\right)$ in Eq. (1) can be simplified as $P(\mathrm{~A} \mid \mathrm{B}) . P(\mathrm{~A} \mid \mathrm{C})$ denotes the cpdf derived from soft data. The cpdf integrating both hard and soft data is updated as

$P(\mathrm{~A} \mid \mathrm{B}, \mathrm{C})=\frac{a^{\tau}}{a^{\tau}+b * c^{\tau}} \in[0,1]$

$a=\frac{1-P(\mathrm{~A})}{P(\mathrm{~A})}$

$b=\frac{1-P(\mathrm{~A} \mid \mathrm{B})}{P(\mathrm{~A} \mid \mathrm{B})}$

$c=\frac{1-P(\mathrm{~A} \mid \mathrm{C})}{P(\mathrm{~A} \mid \mathrm{C})}$.

The parameter $\tau$ is used to adjust the contribution from soft information "C". $\tau=1$ indicates that the two data sets " $B$ " and " $C$ " are independent. For $\tau=0$ soft information is ignored, while for $\tau>1$ the influence of soft data " $C$ " is increased, and it is decreased for $\tau<1$ (Journel, 2002). The sensitivity of parameter $\tau$ in SNESIM was analysed by Liu (2006), and the choice of parameter values for $\tau$ in this study is based on their results.

\subsection{SkyTEM data to soft probability}

A supervised technique (Liu et al., 2005) was applied to retrieve probabilistic information from SkyTEM data. The resistivity data was converted to facies probability data by correlating the facies occurrence in the borehole lithological logs with SkyTEM data. The borehole logs were subdivided into $5 \mathrm{~m}$ intervals in correspondence with the discretization of the SkyTEM data. The lithological logs were categorized as sand or clay and the corresponding resistivity value was recorded. Subsequently, for each resistivity bin (size $1 \Omega \cdot m$ ) the sand probability based on borehole data was computed and plotted against the corresponding resistivity (Fig. 4). The data points were fitted to a truncated polynomial non-linear regression function of resistivity (green line).

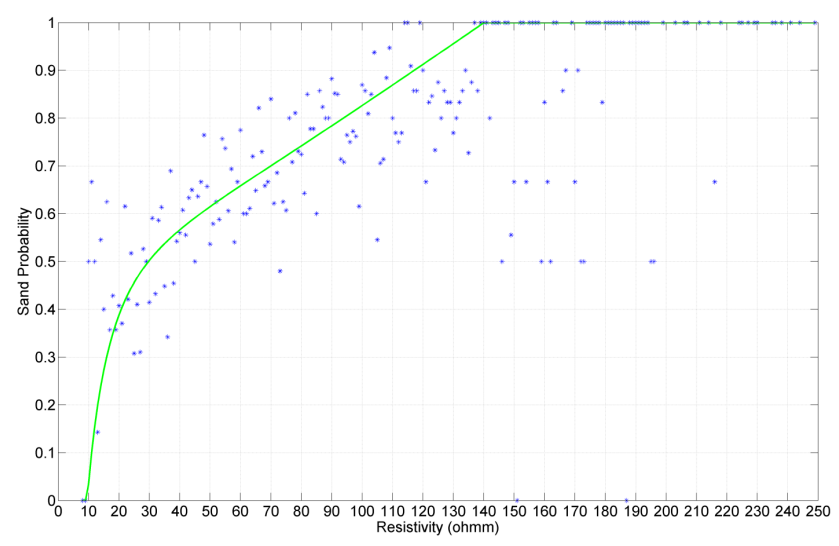

Figure 4. Non-linear regression of sand occurrence against SkyTEM data. Blue points are sand occurrence from borehole data compared to resistivity. The green line is the regression function (Eq. 6), coefficient of determination is 0.80 and RMSE is 0.08 .

Due to data noise, this least-squares curve fitting was only performed for resistivities between 10 and $140 \Omega \cdot \mathrm{m}$. The coefficient of determination is 0.80 and the root mean square error (RMSE) is 0.08 , which indicates that the function represents the correspondence between resistivity $(10-140 \Omega \cdot \mathrm{m})$ and sand probability satisfactorily. Therefore the polynomial regression model was used to convert the 3-D SkyTEM data $(10-140 \Omega \cdot \mathrm{m})$ into a 3-D sand probability map. For resistivities lower than $10 \Omega \cdot \mathrm{m}$ there are only two data points both with sand occurrences of 0 , thus sand occurrence was set to 0 below this value. For resistivities higher than $140 \Omega \cdot \mathrm{m}$, $80 \%$ of data points show sand occurrence at 1 , thus the corresponding sand occurrence was set to 1 . The membership function is therefore expressed as

$P_{\mathrm{s}}= \begin{cases}1 & \text { if } R>140 \Omega \cdot \mathrm{m} \\ 0.0863 & \times(\ln R)^{3}-0.958 \times(\ln R)^{2}+3.759 \\ & \times(\ln R)-4.596 \\ & \text { if } 10 \Omega \cdot \mathrm{m} \ll R \ll 140 \Omega \cdot \mathrm{m} \\ 0 & \text { if } R<10 \Omega \cdot \mathrm{m}\end{cases}$

where $R$ is the resistivity. Figure 5 shows Quaternary sand probability distributions as derived from Eq. (6) for lateral and vertical cross sections.

\subsection{Training image}

Construction of 3-D TI is challenging since geological patterns are usually described in 1-D or 2-D. In this study two kinds of 3-D training images were generated, denoted as TI1 and TI2, respectively.

TI1 was directly converted from SkyTEM data. Based on the resistivity the subsurface was divided into Quaternary sand and Quaternary clay by using a critical resistivity value. According to the 525 borehole logs, the proportion of Quaternary clay is 0.33 . This proportion is assumed to be representative of the study area, although it could be slightly 
Table 1. The mean length distribution in $X, Y$, and $Z$ directions and proportion of Quaternary clay in TI1 and TI2.

\begin{tabular}{|c|c|c|c|c|c|c|c|c|c|c|}
\hline & \multicolumn{3}{|c|}{$X(\mathrm{~m})$} & \multicolumn{3}{|c|}{$Y(\mathrm{~m})$} & \multicolumn{3}{|c|}{$Z(\mathrm{~m})$} & \multirow{2}{*}{$\begin{array}{r}\text { Clay } \\
\text { proportion }\end{array}$} \\
\hline & Min. & Mean & Max. & Min. & Mean & Max. & Min. & Mean & Max. & \\
\hline TI1 & 50 & 400 & 2950 & 50 & 400 & 3200 & 2.5 & 23 & 60 & 0.33 \\
\hline TI2 & 50 & 525 & 2850 & 50 & 454 & 3300 & 2.5 & 21 & 65 & 0.33 \\
\hline
\end{tabular}

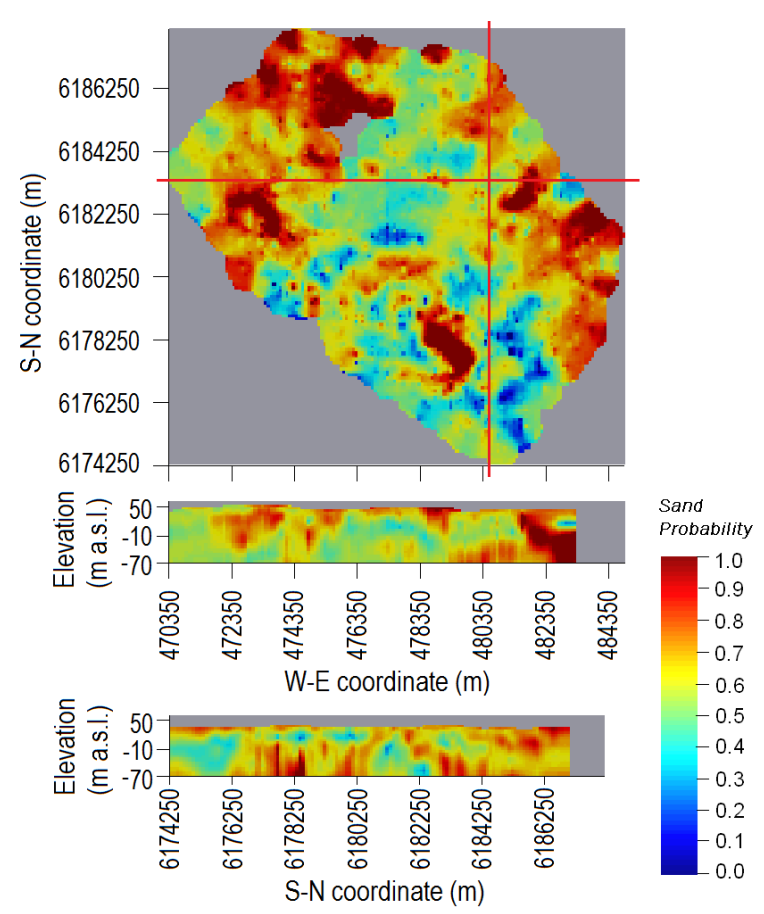

Figure 5. Cross sections of the 3-D map showing the probability of Quaternary sand converted from SkyTEM data. The horizontal plane is taken at $10 \mathrm{~m}$ a.s.l.

biased due to the uneven distribution of boreholes. Figure 6 shows the cumulative distribution function (CDF) of resistivity data. The Quaternary clay proportion of 0.33 corresponds to $41.6 \Omega \cdot \mathrm{m}$ on the CDF curve. Thus, for resistivities below this value the sediment is categorized as Quaternary clay, while for resistivities above this value the sediment is categorized as Quaternary sand. Figure 7 (left) illustrates cross sections of TI1.

TI2 was generated by the TiGenerator (Maharaja, 2008), which is a utility package in SGeMS. The TiGenerator (Maharaja, 2008) provides a method for generating 3-D training images with parametric shapes using non-iterative, unconditional Boolean simulation. The user-defined geometry and orientation of simulated objects can be deterministically or statistically described. With the TiGenerator in SGeMS version 2.1, geobodies with sinusoid, ellipsoid, half-ellipsoid and cuboid shapes can be defined by given geometric parameters such as maximum, median, and minimum radius. The

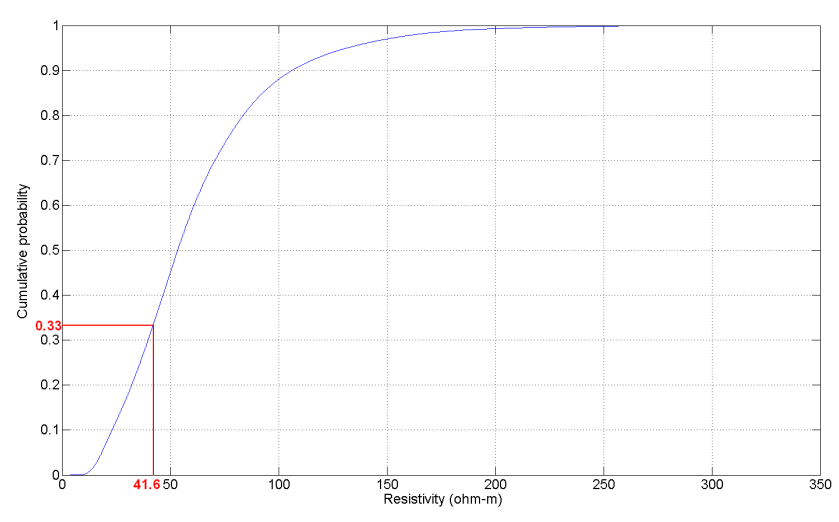

Figure 6. The CDF of SkyTEM data. Resistivity of $41.6 \Omega \cdot \mathrm{m}$ corresponds to a proportion of 0.33 , which is the proportion of Quaternary clay according to borehole data.

geobody is drawn by following a random path until the facies proportion is fulfilled in the simulated grid. The sinusoid shape corresponds to features such as meandering or curvilinear channels, while the cuboid is rectangular. According to the patterns in TI1, the clay lenses are neither channelized nor strongly rectangular, therefore the ellipsoid shape was chosen for the simulation. In TiGenerator the Quaternary sand was used as background facies and the Quaternary clay bodies were simulated with ellipsoid lenses. The target proportion of clay was set to 0.33 as in TI1, and the geometric parameters were determined through the inversion aiming at minimizing the difference between simulated structure and the structure in TI1. The target could also be the information retrieved from borehole data, but in this study the 3-D TI1 depicts the structure in better detail. Therefore, the information on mean length from TI1 was used in the objective function:

$R=\sqrt{\frac{\sum_{t=1}^{j}(E-\tilde{\mathrm{E}})^{2}}{j}}$

where $E$ represents the mean length (minimum, mean and maximum) of clay bodies in $X, Y$ and $Z$ directions from the realizations, and $\tilde{E}$ represents the corresponding item from TI1. $j$ is the total number of items being included and equals 9 in this case. The optimization was based on 20 realizations and the best realization was selected as TI2. The distribution of clay body mean length in TI1 and TI2 is shown in 

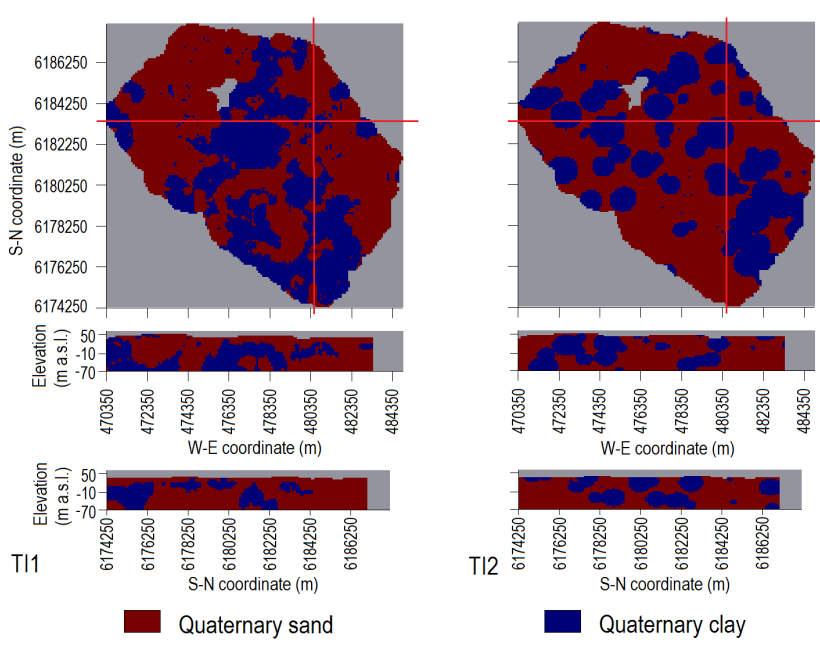

Figure 7. Cross sections of TI1 and TI2. TI1 is converted from SkyTEM data while TI 2 is generated by TiGenerator. The horizontal plane is taken at $10 \mathrm{~m}$ a.s.l.

Table 1. It shows that both TIs have the same clay proportion and minimum mean length of clay bodies in all directions. While it is difficult and time consuming to match the mean and the maximum length in all three directions, the optimized TI2 has a mean length of 525, 454 and $21 \mathrm{~m}$ in $X, Y$ and $Z$ directions, and the corresponding values from TI1 are 400, 400 and $23 \mathrm{~m}$. For the maximum mean length, the difference between TI 2 and TI1 is $3 \%$ in $X$ and $Y$ directions, and $8 \%$ in the $Z$ direction, which indicates that the simulated clay body is in the same size range as that from TI1.

Figure 7 (right) shows the cross sections of TI2. Compared to TI1 (Fig. 7, left), the shapes of the clay bodies are more homogeneous and ellipsoidal than the TI1 clay lenses where the size and shape of clay bodies are more heterogeneous. However, the distribution of clay lenses given by TI2 capture the general trends displayed by TI1 fairly well. Both in the horizontal and vertical direction TI2 shows a tendency of clustering, which is also found in TI1.

\subsection{Groundwater model}

The Groundwater Modelling System (GMS) with the groundwater modelling code MODFLOW-2000 (Harbaugh et al., 2000) was used to assess the effect of the geological structures on the groundwater flow regime, explicitly on simulated hydraulic head. The model area is characterized by high elevations in the central part with several streams flowing towards the model border, and thus no natural hydraulic boundaries could be identified. Instead, a fixed hydraulic head boundary interpolated from observations was employed. The model bottom is Palaeogene clay which serves as no flow boundary. In order to resemble the finely discretized geological model $(100 \mathrm{~m} \times 100 \mathrm{~m} \times 5 \mathrm{~m})$, the Hydrogeologic-Unit Flow (HUF) package (Evan and

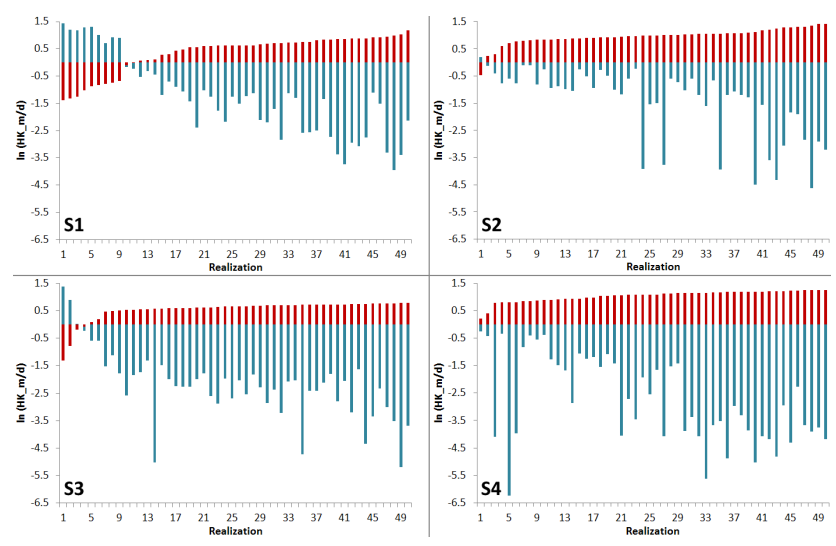

Figure 8. Estimated hydraulic conductivity of Quaternary sand and Quaternary clay using PEST. The realizations are ranked according to the hydraulic conductivity of the Quaternary sand.

Mary, 2000) was used. The groundwater model was discretized into 63 layers with cells of $100 \mathrm{~m} \times 100 \mathrm{~m}$ horizontally, resulting in a total of 792603 active cells. A constant layer thickness of $5 \mathrm{~m}$ is used from layer 6 to 63 , and to avoid dry cells the top layer is $13 \mathrm{~m}$ thick on average (including the unsaturated zone), while the thickness of layer 2 to 5 is $4 \mathrm{~m}$ on average. Groundwater recharge from the DK-model (Henriksen et al., 2003) was applied, resulting in an average recharge rate of $611 \mathrm{~mm}$ year $^{-1}$ in the model area. Groundwater discharges to river, drain and abstraction wells, accordingly the RIV (River), DRT (Drain Return) and WEL (Well) packages were enabled in GMS. The nearest stream discharge station is Q25.32, located to the northeast of the model area (Fig. 1). Based on 16-year data (19902005), the average discharge which is scaled to the model area is $59900 \mathrm{~m}^{3} \mathrm{~d}^{-1}$. A drain was specified for the entire model area with drain level set to $1 \mathrm{~m}$ below terrain, and the drain time constant $\left(1.7 \times 10^{-2} \mathrm{~s}^{-1}\right)$ was taken from the DK-model (Henriksen et al., 2003). There are 165 abstraction wells in the model area with a total pumping rate of $8900 \mathrm{~m}^{3} \mathrm{~d}^{-1}$ (JUPITER). The groundwater model was calibrated against 219 observations of hydraulic head and the river discharge to station Q25.32 using the inversion code PEST (Doherty, 2005).

Based on the calibrated flow model, the particle tracking post-processing code MODPATH (Pollock, 1994) was used to simulate the probabilistic groundwater capture zones. Three wells with screens in Quaternary sediments are included in this simulation (Figs. 9-11). Well 1 is located to the south east and filtered at a depth of $-2.2 \mathrm{~m}$ a.s.l., Well 2 and Well 3 are both located in the central part where higher land surface elevations are found, Well 2 is filtered at $-47.5 \mathrm{~m}$ a.s.1. and Well 3 is filtered at $-52.5 \mathrm{~m}$ a.s.l. A total of 100 particles were assigned to each well and the backward particle tracking was employed. 


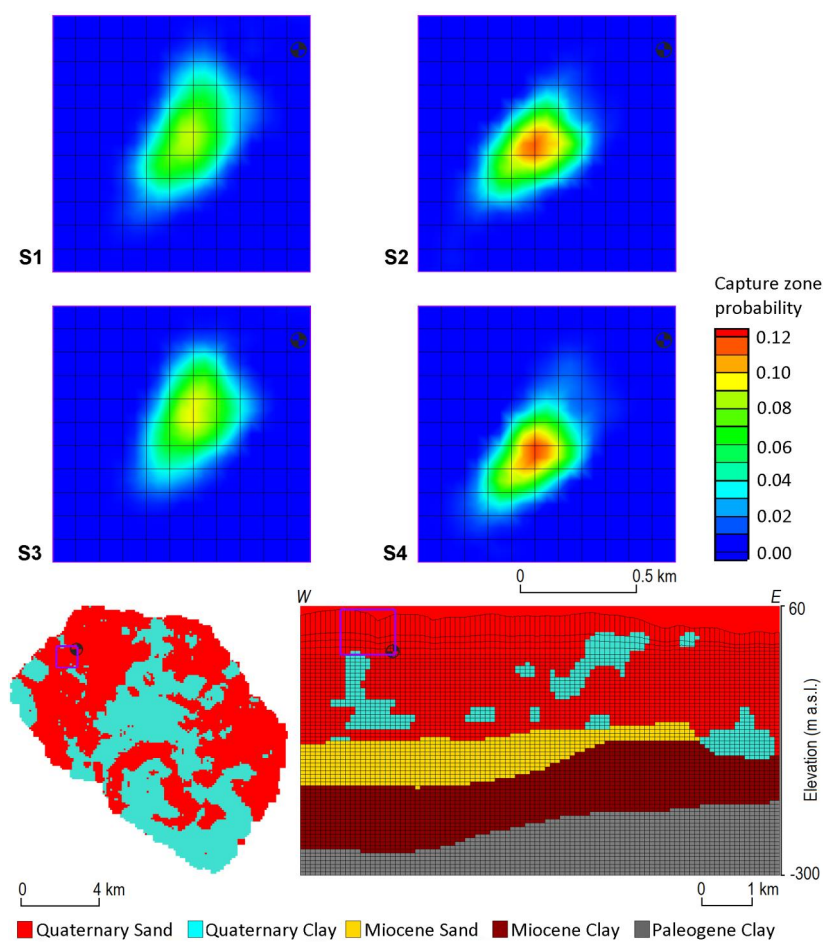

Figure 9. The probabilistic capture zone of Well 1 from each scenario. The well location is illustrated in relation to the geological structure of the TI1.

\subsection{Ensemble analysis}

To test the effect of the training image and soft conditioning on geostatistical realizations, multiple-point geostatistical simulations were carried out by applying four different combinations of TIs and soft conditioning (Table 2). The first two scenarios (S1 and S2) were simulated with TI1. Soft conditioning was applied in S2 but not in S1. The other two scenarios (S3 and S4) were simulated with TI2. Soft conditioning was applied in S4 but not in S3. According to $\mathrm{He}$ et al. (2013) the standard deviation on simulated hydraulic head, based on multiple realizations of the geology, converges to a fixed value as more models are accumulated. A stable value is approached after 30 realizations and in this study 50 realizations were therefore generated in each scenario and subsequently anchored to the steady state groundwater model.

\section{Result and discussion}

\subsection{Model calibration and groundwater head simulations}

With 50 realizations in each scenario, the four scenarios amount to 200 groundwater models. Each model was calibrated against hydraulic head measurements using the inversion code PEST (Doherty, 2005). Initially, a sensitivity analy-
Table 2. Four scenarios of geological realizations used for the multiple-point geostatistical simulations.

\begin{tabular}{ccc}
\hline Scenario & $\begin{array}{c}\text { Training } \\
\text { image }\end{array}$ & $\begin{array}{c}\text { Soft } \\
\text { conditioning }\end{array}$ \\
\hline S1 & TI1 & No \\
S2 & TI1 & Yes \\
S3 & TI2 & No \\
S4 & TI2 & Yes \\
\hline
\end{tabular}

Table 3. RMSE of simulated hydraulic head against observations. The table lists mean, $\mu_{\mathrm{RMSE}}$, and standard deviation, $\sigma_{\mathrm{RMSE}}$, over 50 realizations (where each RMSE value is based on 219 observation wells).

\begin{tabular}{ccc}
\hline Scenario & $\mu_{\text {RMSE }}(\mathrm{m})$ & $\sigma_{\text {RMSE }}(\mathrm{m})$ \\
\hline S1 & 2.6 & 2.2 \\
S2 & 2.6 & 2.1 \\
S3 & 2.6 & 2.2 \\
S4 & 2.6 & 2.2 \\
\hline
\end{tabular}

sis was carried out to identify the parameters to include in the calibration. Based on this analysis the hydraulic conductivities of Quaternary sand, Quaternary clay and Miocene sand were selected as calibration parameters.

The RMSE of simulated hydraulic heads of the calibrated models were used as indicators of model performance. In Table 3 the mean, $\mu_{\mathrm{RMSE}}$, and the standard deviation, $\sigma_{\mathrm{RMSE}}$, of the RMSE of the 50 models in each scenario are listed. The $\mu_{\mathrm{RMSE}}$ is $2.6 \mathrm{~m}$ in all four scenarios while the $\sigma_{\mathrm{RMSE}}$ is $2.2 \mathrm{~m}$ in $\mathrm{S} 1, \mathrm{~S} 3$ and $\mathrm{S} 4$ and is 2.1 in $\mathrm{S} 2$. This implies that models of each scenario are equally well calibrated.

The estimated hydraulic conductivity values of the Quaternary units are shown for each scenario in Fig. 8, while the mean and standard deviation of the estimated values are listed in Table 4. The estimated hydraulic conductivities for Quaternary sand fall in the interval $0.2-4.5 \mathrm{~m} \mathrm{~d}^{-1}$. These are relatively small values for a sandy aquifer material, especially when the lower range of this interval is considered. However, values in the high range of the interval may be within a realistic range for this area (Harrar et al., 2003). A more critical issue is the relative magnitude of Quaternary sand and clay. The hydraulic conductivity of sandy materials should be higher than the corresponding clay material and if this is not the case, it could be an indication of errors in the model structure. In S1 there are nine cases (Fig. 8) where the estimated hydraulic conductivity of clay is higher than the hydraulic conductivity of sand, and there are three such cases in S3. However, this problem appears only once in S2 and is not found in S4. Hence, around 18 and $6 \%$ of the realizations of $\mathrm{S} 1$ and $\mathrm{S} 3$, respectively, show indications of errors in the geological model, while this is only observed in 2 and $0 \%$ of the cases in S2 and S4. 

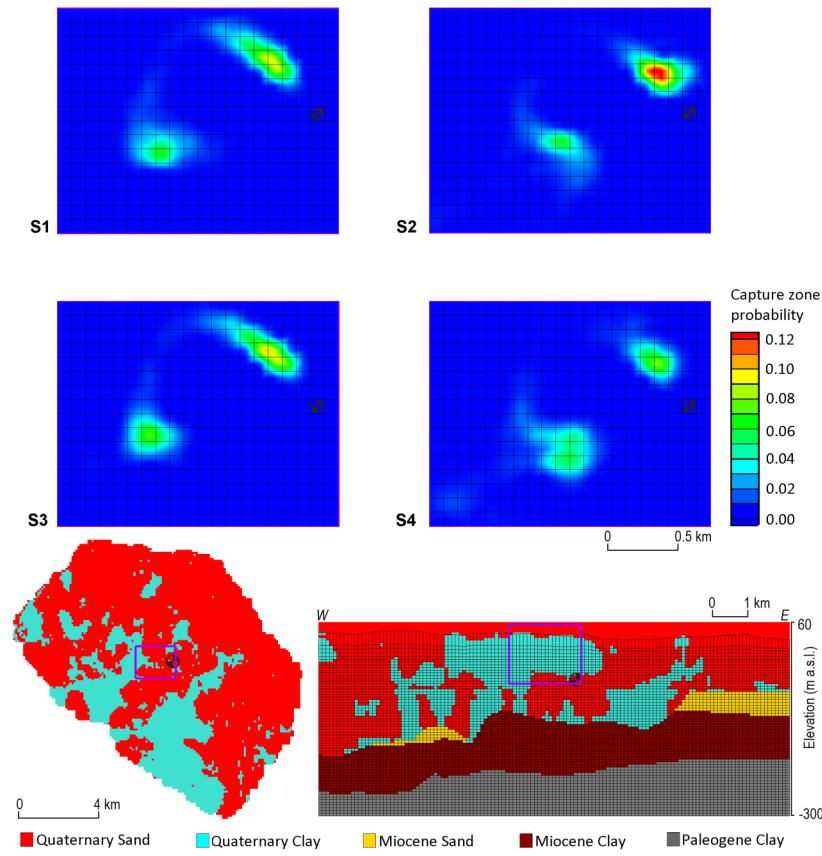

Figure 10. The probabilistic capture zone of Well 2 from each scenario. The well location is illustrated in relation to the geological structure of the TI1.

Table 4. Estimated hydraulic conductivity of Quaternary sand and Quaternary clay using PEST. The values listed are mean and standard deviations $\sigma$ of estimated values over 50 realizations of each scenario (unit: $\mathrm{m} \mathrm{d}^{-1}$ ).

\begin{tabular}{cccccc}
\hline Scenario & \multicolumn{2}{c}{ Quaternary sand } & & \multicolumn{2}{c}{ Quaternary clay } \\
\cline { 2 - 3 } \cline { 5 - 6 } & Mean & $\sigma$ & & Mean & $\sigma$ \\
\hline S1 & 1.7 & 0.8 & & 0.8 & 1.1 \\
S2 & 2.7 & 0.7 & & 0.4 & 0.3 \\
S3 & 1.8 & 0.4 & & 0.3 & 0.6 \\
S4 & 2.9 & 0.5 & & 0.2 & 0.2 \\
\hline
\end{tabular}

In addition, the ratio of hydraulic conductivity between sand and clay material is also an indication of the quality of the estimated geological structure where a high contrast would be expected to be the most reasonable result. The mean horizontal hydraulic conductivities of Quaternary sand and clay are listed in Table 4, and it shows that the largest ratio is found for $\mathrm{S} 4$ (ratio of $14.5 ; 2.9-0.2 \mathrm{~m} \mathrm{~d}^{-1}$ ), and the second largest ratio is estimated for S2 (ratio of $6.8 ; 2.7-$ $0.4 \mathrm{~m} \mathrm{~d}^{-1}$ ), while the lowest ratio is found for S1 (ratio of 2.1; $\left.1.7-0.8 \mathrm{~m} \mathrm{~d}^{-1}\right)$. The difference between the hydraulic conductivity of the two units is also visualized in Fig. 8. These results also clearly show the effect of soft data in the simulation of geological architecture as the most sound results are obtained for scenarios S2 and S4.

The impact of the training images is seen by comparing the first row (S1 and S2) to the second row (S3 and S4) in

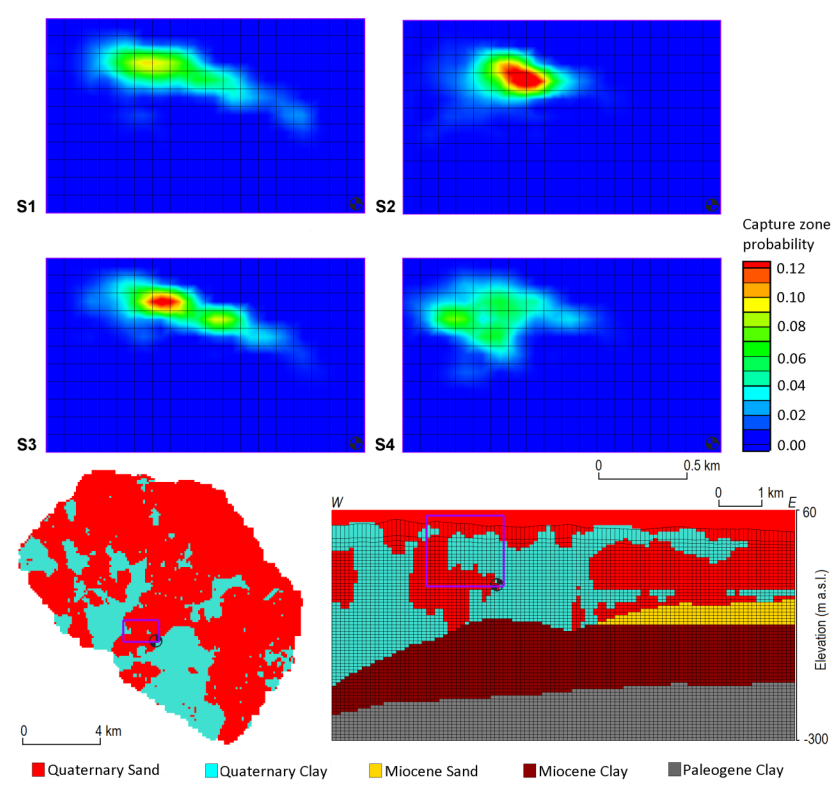

Figure 11. The probabilistic capture zone of Well 3 from each scenario. The well location is illustrated in relation to the geological structure of the TI1.

Fig. 8. Scenarios on the first row use TI1 while the scenarios on the second row use the TiGenerator-based TI2. No apparent statistical discrepancy can be spotted between these two rows, which means that even though TI2 is not directly derived from field data but from a statistical simulation, the TI2-based realizations yield acceptable results. Both with respect to the calibrated groundwater model and the estimated hydraulic parameter values, the choice of training image has a relatively small effect. However, it should be emphasized that TI2 was selected to maximize the similarity between the simulated training image and the field-based training image (TI1), see Table 1.

\subsection{Capture zones}

Probabilistic capture zones were simulated for three abstraction wells screened in both shallow and deep layers. Figures 9-11 show the probabilistic capture zone for these three wells. In each figure the first row illustrates the simulated capture zones based on TI1 (S1 and S2), while the second row represents the corresponding simulations based on TI2 (S3 and S4). As mentioned previously, the thickness of the top numerical layer is $13 \mathrm{~m}$ on average, which is incoherent with the rest of the layers ( $5 \mathrm{~m}$ thickness on average). The thicker top layer was designed to avoid dry cells, but this could also diminish the variability of simulated capture zones, as the geological heterogeneity has been averaged out. Well 1 (located in layer 4) is more sensitive to this effect than the other two wells, since Well 2 and Well 3 are located in layer 13 and layer 14, respectively, and the geological 
heterogeneity in all the other layers still has a significant contribution to the variability of simulated capture zones.

Generally, there is no distinct trend between the first and second row (Figs. 9-11), which again implies that the simulation is not sensitive to the differences between TI1 and TI2. For all three wells, the area of the capture zone is smaller for $\mathrm{S} 2$ and higher probabilities are found compared to S1. However, this is not the case when comparing S4 to S3. In fact, S3 has a more concentrated probabilistic capture zone than that of S4 for Well 2 and Well 3. In the study of He et al. (2013), the simulation of particle travel time was applied on 100 groundwater models with different geological architecture, in combination with a parameter uncertainty analysis of each model. One discovery was that the geological architecture is the most critical factor regarding particle travel time, because it affects the particle travel path. Therefore, the more constrained the probabilistic capture zone is, the less dispersed the path lines are, which is a result of less variation between the structures of the geological realizations. The results illustrated in Figs. 9-11 suggest that there is much less variation among the realizations of $\mathrm{S} 2$ than those of $\mathrm{S} 1$. This is also indicated by the standard deviation of estimated hydraulic conductivity (Table 4), where the uncertainty of S2 is smaller than that of S1, especially for the hydraulic conductivity of sand. However, such tendency is not seen in simulations using TI2 (S3 and S4). Apparently the soft conditioning results in less variation between the realizations, and it decreases more in the TI1-based simulations than in TI2-based simulations. This is also supported by Fig. 12, where the standard deviation of the 50 realizations of each scenario is illustrated. The standard deviation is computed from the binary geological units ( 0 for Quaternary sand and 1 for Quaternary clay). Red colour indicates regions with higher standard deviation, corresponding to higher variability between the 50 realizations. It is obvious that by conditioning on soft data (S2 and S4), the area with higher variability decreases dramatically. $\mathrm{S} 2$ is the scenario with the smallest area of high standard deviations (red colours) among the four scenarios. The explanation for this is data redundancy. Realizations from S2 have been over conditioned and therefore the uncertainty on the probabilistic capture zone has been constrained much more than any of the other scenarios.

The effect of data redundancy is illustrated in Figs. 13 and 14. Figure 13 shows the E-type map (cell-wise arithmetic average) of each scenario. The "E" stands for "expected value" or precisely "conditional expectation" (Remy et al., 2009, p. 37). On the E-type map the cells are more likely to be sand as the colour turns red, and more likely to become clay as the colour turns blue. The cells with dark red or dark blue colours are cells where hard data (borehole data) are located. The effect of soft data can be seen by comparing Fig. 13 to the soft data (sand probability) in Fig. 5. The E-type of S1 and S3 shows almost no similarity to the soft data in Fig. 5, while the E-type of S2 and S4 show patterns that are very similar to the soft data. Figure 14 illustrates the CDF of soft data
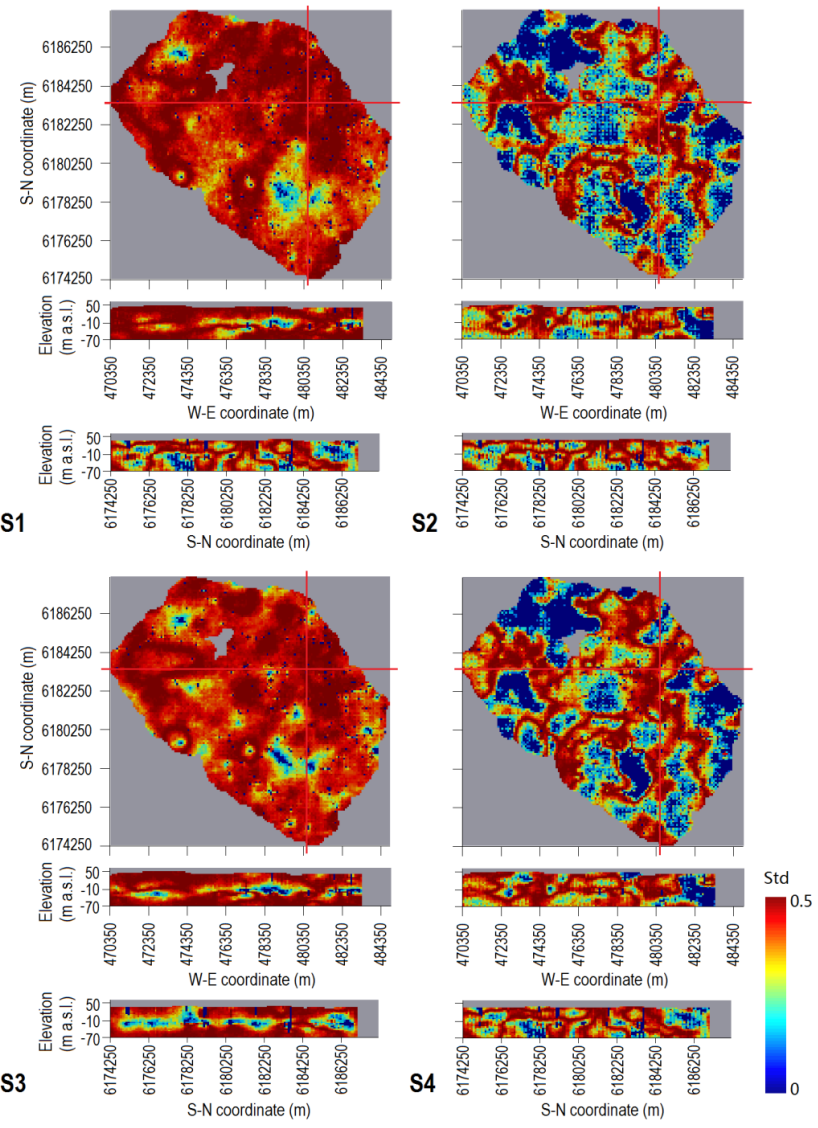

Figure 12. Map of standard deviation over the 50 realizations of each scenario. The computation of standard deviation is based on binary geological units ( 0 for Quaternary sand and 1 for Quaternary clay). The standard deviations are 0 at cells where the boreholes are located. The horizontal plane is taken at $10 \mathrm{~m}$ a.s.l.

together with a Q-Q plot of the E-type map from each scenario. In the $\mathrm{Q}-\mathrm{Q}$ plot the $x$ axis shows the sand probability from the soft data, while the $y$ axis shows the corresponding probability from the E-type map. The black line is the CDF of sand probability based on soft data. The closer the Q-Q plot is to the black line, the more similar the sand probability distribution of the realizations is to the soft data. While the plot for S1 (yellow symbols) is far from the black line, the plot for S2 (blue symbols) is much closer. The red plot (S4) is also closer to the black line than the purple plot (S3). Both scenarios with soft conditioning (blue and red symbols) are much lower than the black line on the low sand probability part, while higher than the black line on the high sand probability part. But for the other scenarios, the plots are always lower than the black line. This shows the effect of soft conditioning. In addition, the curve representing S2 (blue symbols) is higher than for S4 (red symbols), and this can be explained by data dependency. Both TI1 and soft data are derived from SkyTEM data, and although they were processed in different ways, they are not totally independent. In Eq. (2), the 

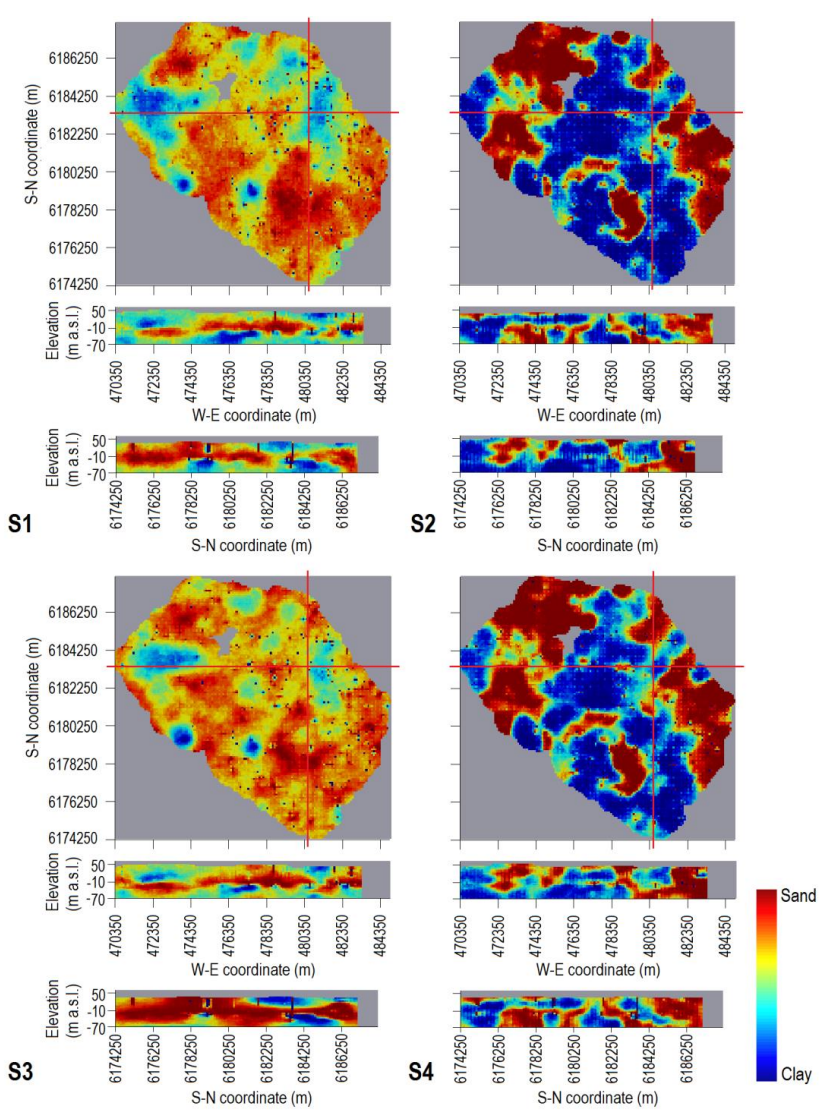

Figure 13. E-type estimation maps generated from 50 realizations of the geology of each scenario. The cells where the boreholes are located have the deepest colours. The horizontal plane is taken at $10 \mathrm{~m}$ a.s.l.

parameter $\tau$ is used to adjust the dependence between the two data sets $B$ and $C$ (representing the training image and the soft data in the current case). To make S2 and S4 comparable, the parameter $\tau$ is specified to 1.0 in both cases. Liu (2006) pointed out that using a value of 1.0 generates the most robust results. In Fig. 14 the plot for S2 (blue) is lower than the black line in the low probability part, while it is located above the black line in the high probability part, indicating that the S2 realizations are over conditioned. In contrast, as TI2 is remotely related to the soft data, the soft conditioning on S4 improves the simulations, but the effect of data redundancy is weaker than that in S2. Therefore, integration of the training image constructed using the TiGenerator (TI2) with the SkyTEM-based soft data is more sound than combining TI1 and soft data that both are based on SkyTEM data. Journel (2002) found that when $\tau<1$ the influence of additional data is decreased. Therefore, another scenario (S5) was added where TI1 and soft data were used, but the parameter $\tau$ is set to 0.5 . S5 corresponds to the green plot in Fig. 14, and it is located right between $\mathrm{S} 1$ and $\mathrm{S} 2$, which illustrates the effect of decreasing $\tau$.

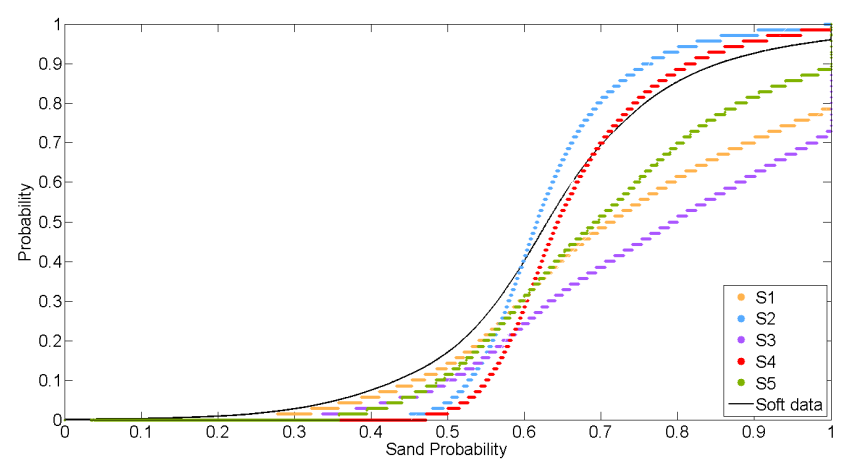

Figure 14. Black line indicates the CDF of the sand probability from soft data. Point plots are Q-Q plots of the average of realizations from each scenario against soft data.

\section{Conclusions}

This study is one of the first to evaluate the effect of highresolution airborne electromagnetic data in multiple-point geostatistical simulations. It demonstrates how the 3-D highresolution airborne electromagnetic data can be used as the TI as well as secondary data for soft conditioning. The sensitivity of model predictions to the TI and soft conditioning has also been analysed. The SkyTEM-derived training image which resembles the actual geological structure of the site is evaluated against the parametric training image generated by the object-based TiGenerator. The TI from the TiGenerator is an abstract depiction of the geological structure with parameterized geometry. Although it is not derived directly from field data, it is found to be a reasonable input to MPS. The comparison of simulations of groundwater head and capture zone indicates that in cases where knowledge of the overall geological structure is available, an object-based training image may be just as good as a training image based on geological interpretations of the actual site. Although this conclusion was based on groundwater heads and capture zones, it is expected that similar conclusions would be obtained from simulations of groundwater age or solute transport as these variables are, similar to capture zones, very much dependent on path lines and velocities, which are sensitive to geological heterogeneity (He et al., 2013). This study was based on a highly heterogeneous two-facie geological system where the exact shape and location of the clay lenses may not affect the results from the groundwater model significantly. However, if systems with curvilinear structures such as buried valleys are considered, the geological architecture may have a larger impact on groundwater flow and the choice of training image could therefore be more important. However, more testing is required to assess if the conclusions from the current study can be transferred to other types of geological environments.

By further conditioning on secondary data, the simulated geological structure is improved. This is revealed through the results from the parameter calibration where the likelihood of 
obtaining a realistic parameter set is much higher if soft data is used for conditioning. However, when applying soft conditioning, the dependence of different data sets has to be taken into account. If the training image and the soft conditioning data are based on the same source of information, the resulting geological realizations may be over-conditioned. Overconditioning may not decrease the accuracy of the individual geological model, and this is proved by the calibration where each model from S2 yields reasonable parameter estimates. However, over-conditioning decreases the uncertainty among simulated geological models, which results in underprediction of the uncertainties in transport simulations. This is demonstrated for the examined case where high-resolution SkyTEM data is used as both training image and soft conditioning which results in a higher reduction in capture zone uncertainty than if SkyTEM was only used for soft conditioning.

Therefore, it is recommended to use independent data sources for generating the training image and the soft data. Based on the present study, the best result is obtained if the TiGenerator is used for defining the training image and the geophysical data for soft conditioning. The information required by the TiGenerator may be derived from expert knowledge of the geological structure of the site or derived from analysis of mapped geology at a site with comparable geology. Alternatively, a Q-Q plot analysis could be carried out and the contribution from soft data on the realization should be decreased. It is, however, (1) problematic to estimate the optimal level of information which should be obtained from the soft data and (2) time consuming to carry out the analysis.

Edited by: A. Guadagnini

\section{References}

Bourges, M., Mari, J.-L., and Jeannée, N.: A practical review of geostatistical processing applied to geophysical data: methods and applications, Geophys. Prospect., 60, 400-412, 2012.

Carle, S. F. and Fogg, G. E.: Transition probability-based indicator geostatistics, Math. Geol., 28, 453-76, 1996.

Clement, W. P. and Ward, A.: GPR surveys across a prototype surface barrier to determine temporal and spatial variations in soil moisture content, Chap. 23, in: The Handbook of Agricultural Geophysics, edited by: Allred, B. J., Ehsani, M. R., and Daniels, J. J., American Society of Agricultural Engineers, CRC Press, 305-315, 2008.

Comunian, A., Renard, P., Straubhaar, J., and Bayer, P.: Threedimensional high resolution fluvio-glacial aquifer analog - Part 2: geostatistical modeling, J. Hydrol., 405, 10-23, 2011.

Comunian, A., Renard, P., and Straubhaar, J.: 3D multiple-point statistics simulation using 2D training images, Comput. Geosci. 40, 49-65, 2012.
Coz, M. L., Genthon, P., and Adler, P. M.: Multiple-point statistics for modeling facies heterogeneities in a porous medium: the Komadugu-Yobe Alluvium, Lake Chad Basin, Math. Geosci., 43, 861-878, 2011.

Delhomme, J. P.: Spatial variability and uncertainty in groundwater flow parameters: a geostatistical approach, Water Resour. Res., 15, 269-280, 1979.

Deutsch, C. V. and Journel, A. G.: GSLIB Geostatistical Software Library and User's Guide, Oxford University Press, New York, 1992.

Deutsch, C. V. and Wang, L.: Hierarchical object-based stochastic modeling of fluvial reservoirs, Math. Geol., 28, 857-880, 1996.

Doherty, J.: PEST: Model Independent Parameter Estimation, 5th Edn. of user manual, Watermark Numerical Computing, Brisbane, Australia, 2005.

Evan, R. A. and Mary, C. H.: Documentation of the hydrogeologicunit flow (HUF) package, US Geological Survey Open File Rep 00-342, US Geological Survey, Denver, CO, USA, 2000.

Goovaerts, P.: Geostatistics for Natural Resources Evaluation, Oxford University Press, New York, 483 pp., 1997.

Guardiano, F. B. and Srivastava, R. M.: Multivariate Geostatistics: Beyond Bivariate Moments, in: Geostatistics Tróia '92, Quantitative Geology and Geostatistics, edited by: Soares, A., Kluwer Academic Publishers, Dordrecht, Netherlands, 133-144, 1993.

Harbaugh, A. W., Banta, E. R., Hill, M. C., and McDonald, M. G.: MODFLOW-2000, the US Geological Survey modular groundwater model - user guide to modularization concepts and the Ground-Water Flow Process: US Geological Survey Open-File Report 00-92, US Department of Interior, Reston, VA, USA, 121 pp., 2000.

Harrar, W. G., Sonnenborg, T. O., and Henriksen, H. J.: Capture zone, travel time, and solute-transport predictions using inverse modeling and different geological models, Hydrogeol. J., 11, 536-548, 2003.

He, X., Sonnenborg, T. O., Jørgensen, F., Høyer, A.-S., Møller, R. R., and Jensen, K. H.: Analyzing the effects of geological and parameter uncertainty on prediction of groundwater head and travel time, Hydrol. Earth Syst. Sci., 17, 3245-3260, doi:10.5194/hess17-3245-2013, 2013.

Henriksen, H. J., Troldborg, L., Nyegaard, P., Sonnenborg, T. O., Refsgaard, J. C., and Madsen, B.: Methodology for construction, calibration and validation of a national hydrological model for Denmark, J. Hydrol., 280, 52-71, 2003.

Hoffmann, J.: The future of satellite remote sensing in hydrogeology, Hydrogeol. J., 13, 247-250, 2005.

Hu, L. Y. and Chugunova, T.: Multiple-point geostatistics for modeling subsurface heterogeneity: a comprehensive review, Water Resour. Res., 44, W11413, doi:10.1029/2008WR006993, 2008.

Huysmans, M. and Dassargues, A.: Application of multiple-point geostatistics on modeling groundwater flow and transport in a cross-bedded aquifer (Belgium), Hydrogeol. J., 17, 1901-1911, 2009.

Huysmans, M. and Dassargues, A.: Modeling the effect of clay drapes on pumping test response in a cross-bedded aquifer using multiple-point geostatistics, J. Hydrol., 450-451, 159-167, 2012.

Høyer, A.-S., Lykke-Andersen, H., Jørgensen, F., and Auken, E.: Combined interpretation of SkyTEM and high-resolution seismic data, Phys. Chem. Earth A/B/C, 36, 1386-1397, 2011. 
Johnson, N. M.: Characterization of alluvial hydrostratigraphy with indicator semivariograms, Water Resour. Res., 31, 3217-3227, 1995.

Journel, A. G.: Geostatistics: roadblocks and challenges, in: Geostatistics Tróia '92, edited by: Soares, A., Springer Netherlands, Dordrecht, 213-224, 1993.

Journel, A. G.: Combining knowledge from diverse sources: an alternative to traditional data independence hypotheses, Math. Geol., 34, 573-596, 2002.

Journel, A. G.: Beyond covariance: the advent of multiple-point geostatistics, in: Geostatistics Banff 2004, Quantitative Geology and Geostatistics, edited by: Leuangthong, O. and Deutsch, C. V., Springer Netherlands, Dordrecht, Netherlands, 225-233, 2005.

Klise, K. A., Weissmann, G. S., McKenna, S. A., Nichols, E. M., Frechette, J. D., Wawrzyniec, T. F., and Tidwell, V. C.: Exploring solute transport and streamline connectivity using lidar-based outcrop images and geostatistical representations of heterogeneity, Water Resour. Res., 45, W05413, doi:10.1029/2008WR007500, 2009.

Liu, Y.: Using the Snesim program for multiple-point statistical simulation, Comput. Geosci., 32, 1544-1563, 2006.

Liu, Y., Harding, A., Abriel, W., and Strebelle, S.: Multiple-point simulation integrating wells, three-dimensional seismic data, and geology, AAPG Bull., 88, 905-921, 2004.

Liu, Y., Harding, A., Gilbert, R., and Journel, A. G.: A workflow for multiple-point geostatistical simulation, in: Geostatistics Banff 2004, Quantitative Geology and Geostatistics, edited by: Leuangthong, O. and Deutsch, C. V., Springer Netherlands, Dordrecht, Netherlands, 245-254, 2005.

Lubczynski, M. and Roy, J.: Hydrogeological interpretation and potential of the new magnetic resonance sounding (MRS) method, J. Hydrol., 283, 19-40, 2003.

Maharaja, A.: TiGenerator: object-based training image generator, Comput. Geosci., 34, 1753-1761, 2008.

Okabe, H. and Blunt, M. J.: Pore space reconstruction using multiple-point statistics, J. Pet. Sci. Eng., 46, 121-137, 2005.

Okabe, H. and Blunt, M. J.: Pore space reconstruction of vuggy carbonates using microtomography and multiple-point statistics, Water Resour. Res., 43, W12S02, doi:10.1029/2006WR005680, 2007.
Pollock, D. W.: User's guide for MODPATH/MODPATH-PLOT a particle tracking post-processing package for MODFLOW, the US Geological Survey finite-difference ground-water flow model (SuDoc I 19.76:94-464). The Survey Earth Science Information Center, Open-File Reports Section, distributor, 1994.

Rasmussen, E. S., Dybkjær, K., and Piasecki, S.: Lithostratigraphy of the Upper Oligocene - Miocene succession of Denmark, Geological Survey of Denmark and Greenland Bulletin, Geological Survey of Denmark, Copenhagen, Denmark, 22, 92 pp., 2010.

Remy, N., Boucher, A., and Wu, J.: Applied Geostatistics with SGeMS: A User's Guide, Cambridge University Press, 2009.

Scharling, P. B., Rasmussen, E. S., Sonnenborg, T. O., Engesgaard, P., and Hinsby, K.: Three-dimensional regional-scale hydrostratigraphic modeling based on sequence stratigraphic methods: a case study of the Miocene succession in Denmark, Hydrogeol. J., 17, 1913-1933, 2009.

Stisen, S., Sonnenborg, T. O., Højberg, A. L., Troldborg, L., and Refsgaard, J. C.: Evaluation of climate input biases and water balance issues using a coupled surface-subsurface model, Vadose Zone J., 10, 37-53, 2011.

Strebelle, S.: Conditional simulation of complex geological structures using multiple-point statistics, Math. Geol., 34, 1-21, 2002.

Strebelle, S. B.: Sequential simulation for modeling geological structures from training images, in: Stochastic Modeling and Geostatistics: Principles, Methods, and Case Studies, Volume II: AAPG Computer Applications in Geology 5, edited by: Coburn, T. C., Yarus, J. M., and Chambers, R. L., AAPG, Tulsa, OK, USA, 139-149, 2006.

Strebelle, S. B., Payrazyan, K., and Caers, J.: Modeling of a deepwater turbidite reservoir conditional to seismic data using multiple point geostatistics. Society of Petroleum Engineers (SPE) Annual Conference and Technical Meeting, SPE 77429, San Antonio, TX, 2002.

Sørensen, K. I. and Auken, E.: SkyTEM - a new high-resolution helicopter transient electromagnetic system, Explor. Geophys., 35, 191-199, 2004.

Wingle, W. L. and Poeter, E. P.: Uncertainty associated with semivariograms used for site simulation, Ground Water, 31, 725-734, 1993. 